\title{
In Vitro Evaluation of Essential Oils Derived from Piper nigrum (Piperaceae) and Citrus limonum (Rutaceae) against the Tick Rhipicephalus (Boophilus) microplus (Acari: Ixodidae)
}

\author{
Rafaelle Vinturelle, ${ }^{1,2}$ Camila Mattos, ${ }^{1,2}$ Jéssica Meloni, ${ }^{1,2}$ Jeane Nogueira,,4 \\ Maria Júlia Nunes, ${ }^{5,6}$ Itabajara S. Vaz Jr., ${ }^{7,8}$ Leandro Rocha, ${ }^{3,4}$ Viviane Lione, \\ Helena C. Castro, ${ }^{2}$ and Evelize Folly das Chagas ${ }^{1,2,8}$ \\ ${ }^{1}$ Laboratório de Estudos em Pragas e Parasitos, Universidade Federal Fluminense, IB, \\ Departamento de Biologia Celular e Molecular-GCM, Niterói, RJ, Brazil \\ ${ }^{2}$ Programa de Pós-Graduação em Ciências e Biotecnologia, Universidade Federal Fluminense, Niterói, RJ, Brazil \\ ${ }^{3}$ Laboratório de Tecnologia de Produtos Naturais, Faculdade de Farmácia, Universidade Federal Fluminense, Niterói, RJ, Brazil \\ ${ }^{4}$ Programa de Pós-Graduação em Ciências Aplicadas a Produtos para Saúde, Departamento de \\ Farmácia e Administração Farmacêutica, Faculdade de Farmácia, Universidade Federal Fluminense, Rua Doutor Mário Viana 523, \\ 24241-000 Niterói, RJ, Brazil \\ ${ }^{5}$ Bellarome Aromoterapia, Centro, Rio de Janeiro, RJ, Brazil \\ ${ }^{6}$ Centro Universitário Augusto Motta (UNISUAM), Rio de Janeiro, RJ, Brazil \\ ${ }^{7}$ Centro de Biotecnologia e Faculdade de Veterinária, Universidade de Federal do Rio Grande do Sul, Porto Alegre, RS, Brazil \\ ${ }^{8}$ Instituto Nacional de Ciências e Tecnologia em Entomologia Molecular (INCT-EM), Rio de Janeiro, RJ, Brazil \\ ${ }^{9}$ Faculdade de Farmácia, Universidade Federal do Rio de Janeiro, Rio de Janeiro, RJ, Brazil
}

Correspondence should be addressed to Evelize Folly das Chagas; evelizefolly@yahoo.com.br

Received 30 March 2017; Accepted 25 July 2017; Published 8 October 2017

Academic Editor: Jan A. Miernyk

Copyright ( 2017 Rafaelle Vinturelle et al. This is an open access article distributed under the Creative Commons Attribution License, which permits unrestricted use, distribution, and reproduction in any medium, provided the original work is properly cited.

\begin{abstract}
The present research aimed to study the chemical composition and acaricidal activity of Citrus limonum and Piper nigrum essential oils against the cattle tick Rhipicephalus microplus. GC-MS analysis of $C$. limonum essential oil showed limonene (50.3\%), $\beta$-pinene (14.4\%), and $\gamma$-terpinene (11.7\%) as the major components; $P$. nigrum oil was mainly composed of $\beta$-caryophyllene $(26.2 \%), \sigma$ ocymene (5.8\%), and $\alpha$-pinene (5.5\%). Acaricide activity was evaluated at concentrations of 2.5, 5.0, and $10.0 \%$ (v/v) of each plant oil, as well as $1: 1$ combination of both oils ( $5 \%: 5 \%, 2.5 \%: 2.5 \%$, and $1.25 \%: 1.25 \%$ each), by immersing engorged $R$. microplus females for one minute. The LC90 of oils from C. limonum, P. nigrum, and the combination were 4.9\%, 14.8\%, and 5.1\%, respectively. C. limonum essential oil caused $100 \%$ mortality of engorged females at the highest concentration (10\%). P. nigrum essential oil inhibited egglaying by up to $96 \%$ in a concentration-dependent manner, suggesting it reduces tick fecundity. When combined, the oils presented toxicity as to C. limonum oil alone, but with stronger inhibition of oviposition (5\%:5\%), indicating a possible additive effect against R. microplus. The present data provide support for further investigation of novel natural products to control bovine tick infestations.
\end{abstract}

\section{Introduction}

The tick Rhipicephalus (Boophilus) microplus (Canestrini, 1887) is an ectoparasite of cattle [1], present in tropical and subtropical areas of America, Africa, Asia, and Australia in latitudes between $32^{\circ} \mathrm{N}$ and $32^{\circ} \mathrm{S}[2,3]$. About the damage caused by this parasite, direct losses in the production of milk and meat, leather damage caused by inflammatory reactions at the sites of tick attachment, appearance of myiasis, and the transmission of diseases such as bovine tick fever (caused by protozoa of the genus Babesia and by bacteria of the genus Anaplasma) could be mentioned [4]. The economic losses of 
Brazil related to ticks are estimated by 3.24 billion dollars a year, represented by the direct action of the parasite in the animals and by the cost of the control systems [5].

One of the strategies to minimize the economic losses caused by this pest involves reducing tick populations to economically acceptable levels [6]. But the inherent problems in controlling this parasite are acaricide resistance, and environmental residues resulted in only partial success of tick control [7]. The searches for environmentally safe products have accelerated the research on botanical acaricides $[8,9]$. Plants have been used as food, spices, and medicines for thousands of years. These medicines initially took the form of crude drugs such as a variety of plants formulations. Natural products have been the origin of many important molecules in drug discoveries. Different culinary herbs have been screened for their biological activities. The active ingredients from plants are known to possess insecticidal, growth inhibiting, antimoulting, and repellent activities [8]. Thus, there is increasing interest in alternative methods for tick control and growing demand for nonchemical products in livestock that are safer to animals and the environment [10, 11]. Botanical alternatives, such as essential oils, are currently receiving particular attention [12].

In Brazil, the Rutaceae family comprises about 38 genera and 22 species [13]. Citrus limonum (L.) comprises 3 species and various hybrids. Species of this genus are known to show monoterpenes and sesquiterpenes, such as limonene and $\alpha$ pinene $[14,15]$. Essential oils of this kind have been evaluated for presenting biological activities such as insecticide, cytotoxic, and antibacterial activities [16].

Piper nigrum (L.), popularly known as black pepper, is a member of family Piperaceae [17, 18]. The genus Piper includes more than 1000 species, but the best known are $P$. nigrum, Piper longum, and Piper betle [19, 20]. The fruits of $P$. nigrum contain piperine, a compound that has already shown leishmanicidal activity [21]. Furthermore, secondary metabolites of this species possess active compounds with insecticidal activity, antibacterial, antifungal, and others [20, 22].

The aim of this work is to develop natural products, like essential oils, for the combat of the cattle tick.

\section{Materials and Methods}

2.1. Essential Oil. Citrus limonum and Piper nigrum essential oils were obtained commercially in Bellarome, RJ, Brazil commercial Ltda. According to the company, C. limonum essential oil was obtained from the juice industry peel residue, which was pressed and the oil was washed out with water of the material, while the dried fruit of P. nigrum was steam distilled for 60 minutes to obtain the essential oil.

2.2. Analysis by GC/MS. The crude essential oil was analyzed on a GC-MS QP2010 (SHIMADZU) gas chromatograph equipped with a mass spectrometer using electron impact ionization detection. The gas chromatographic (GC) conditions were as follows: injector temperature: $260^{\circ} \mathrm{C}$; detector temperature: $290^{\circ} \mathrm{C}$; carrier gas (Helium): flow rate $1 \mathrm{~mL} / \mathrm{min}$; and split injection with split ratio $1: 40$. Oven temperature was raised from $60^{\circ} \mathrm{C}$ to $290^{\circ} \mathrm{C}$ at a rate of $3^{\circ} \mathrm{C} / \mathrm{min}$. One microliter of each sample, dissolved in $\mathrm{CH} 2 \mathrm{Cl} 2$ $(1: 100 \mathrm{mg} / \mu \mathrm{L})$, was injected on a RTX-5 column (i.d. = $0.25 \mathrm{~mm}$, length $30 \mathrm{~m}$, film thickness $=0.25 \mu \mathrm{m})$. Mass spectra (MS) were recorded $70 \mathrm{eV}$ and scan rate of $1 \mathrm{scan} / \mathrm{s}$. The retention indices were calculated by interpolation of retention times of the substances to the retention times of a mixture of aliphatic hydrocarbons (C7-C40) (Sigma-Aldrich Corporation, St Louis, MO) analyzed in the same conditions (Van den Dool H. \& Kratz). The identification of substances was performed by comparison of their retention indices and mass spectra with those reported in literature [23]. The MS fragmentation pattern of compounds was also checked with NIST mass spectra libraries.

2.3. Preparation of the Samples for Acaricidal Test. The experiment was conducted in two phases. Essential oils were tested separately and after mixing were performed at equal concentrations, in 1:1 proportions (50\% Citrus limonum and $50 \%$ Piper nigrum). The essential oils of C. limonum and P. nigrum were dissolved in an aqueous solution with $2 \%$ dimethyl sulfoxide (v/v) as an emulsifying agent, as described by Gazim et al. in [24]. Solutions were serially diluted in order to obtain the concentrations of $2.5 \%, 5 \%$, and $10 \%$ $(\mathrm{v} / \mathrm{v})$, obtaining a final volume of $5 \mathrm{~mL}$. The emulsifying solution ( $2 \%$ DMSO) was used as the negative control. A control with water was also carried out. Amitraz $(2 \mu \mathrm{L} / \mathrm{mL})$ and Deltamethrin $(1 \mu \mathrm{L} / \mathrm{mL})$ in water were used as positive control. The test was repeated three times in duplicate.

2.4. Rhipicephalus microplus Ticks for Bioassays. The engorged females ticks of $R$. (B.) microplus were collected from infested animals from a farm of Rio Grande do Sul (Brazil) without history of acaricide use. The tick population was maintained based on artificial infestations on calves at Faculdade de Veterinária from Federal University of Rio Grande do Sul (UFRS), Brazil. All experiments were conducted following the guidelines of the Ethics Committee on Animal Experimentation of UFRS and FEPAGRO. The ticks were thoroughly washed with tap water, dried on filter paper towel, and used in the adult immersion test.

2.5. Adult Immersion Test (AIT). The AIT was performed as described by Drummond et al. [25] with minor modifications. The ticks were distributed to groups randomly (20 engorged females per group). The different groups of $R$. (B.) microplus were immersed for $1 \mathrm{~min}$ in $5 \mathrm{~mL}$ of the respective concentrations $(2.5 \%, 5 \%$, and $10 \%)$ of C. limonum and $P$. nigrum by placing them directly into a $50 \mathrm{~mL}$ Falcontype tube which was gently agitated at room temperature. In experiments of additive effects we used the ratio $1: 1$ ( $\mathrm{vol} / \mathrm{vol}$ ) of each oil, with a final concentration of $2.5 \%$, $5 \%$, and $10 \%$. Ticks were recovered from the solutions and dried and each group was transferred to Petri dish $(9 \mathrm{~cm}$ diameter, $1,5 \mathrm{~cm}$ high), weighed, and kept in BOD incubator at a temperature of $28^{\circ} \mathrm{C}$ and relative humidity of $70-80 \%$ for oviposition. This experiment was performed three times in duplicate. The emulsifying solution ( $2 \%$ DMSO) was used as the negative control, while Amitraz $(2 \mu \mathrm{L} / \mathrm{mL})$ and 
Deltamethrin $(1 \mu \mathrm{L} / \mathrm{mL})$ in water were used as positive control. The mortality was observed during 15 days. The dead ticks were diagnosed based on three specific signs and features: increasing cuticle darkness and stopping Malpighian tube movement and hemorrhagic skin lesions. After 15 days, the eggs laid were placed in glass tube, weighed, and observed separately at the same condition of incubation for the next 30 days for visual estimation of hatching rate.

The percentage inhibition of oviposition was calculated as follows.

Reproductive index $(\mathrm{RI})$ = average weight of eggs laid (mg)/average weight of females before treatment (g).

Percentage inhibition of oviposition $(\mathrm{IO} \%)=\mathrm{RI}$ of control group - RI of treated group/RI control group $\times 100$.

2.6. Statistical Analyses. Data were expressed as the mean \pm standard error of the mean (SEM). Groups were compared using ANOVA one-way test. A $p$ value of less than 0.05 was considered significant. Statistical analysis was performed using GraphPad Prism 6.0 (GraphPad Software Inc., San Diego, USA) software.

The efficacy was assessed by measuring female mortality (\%) and the lethal concentrations for 50\% (LC50) and 90\% (LC90) with their 95\% confidence limits (CL) values were estimated by applying regression equation analysis to the probit transformed data of mortality.

\section{Results}

3.1. Identification of the Components by GC/MS. The composition of the oil from Citrus limonum and Piper nigrum, together with the relative retention index and percentage of the identified compounds, is listed in Table 1. A total of 29 compounds representing $96.3 \%$ of the total oil were identified from C. limonum essential oil. The chromatographic profile of $C$. limonum showed a complex mixture of monoterpenes $(90.3 \%)$ and sesquiterpenes (3.1\%). C. limonum oil was composed mainly by the monoterpenes limonene $(50.3 \%), \beta$ pinene (14.4\%), and $\gamma$-terpinene (11.7\%).

In P. nigrum essential oil, 42 compounds were identified, comprising $89 \%$ of the oil. The essential oil was characterized by the presence of sesquiterpenes (58.9\%) and monoterpenes (26.3\%). The sesquiterpene $\beta$-caryophyllene was identified as the major compound, representing $26.2 \%$ of the oil, followed by the monoterpenes hydrocarbons $\sigma$-ocymene $(5.8 \%)$ and $\alpha$-pinene (5.5\%).

\subsection{Rhipicephalus (Boophilus) microplus Engorged Female} Mortality Rate. Laboratory tests were carried out to determine the toxicity of the essential oils from $C$. limonum and $P$. nigrum on engorged females of $R$. (B.) microplus. The results referents to mortality rate of engorged females after adult immersion test (AIT) are present in Figure 1 and Table 2. Essential oil from C. limonum exhibited $90 \%$ of mortality on engorged females in the highest concentration tested after $48 \mathrm{~h}$, reaching $100 \%$ at the end of the experiments (day 16). At concentration of 5\%,C. limonum achieved approximately $80 \%$ mortality rate in the fourth day and getting the most for $90 \%$ mortality at the 12 th day. The $2.5 \%$ C. limonum essential oil led to $50 \%$ mortality rate on day 16 after treatment (Figure 1(a)).

The essential oil of $P$. nigrum also demonstrated high efficacy against $R$. (B.) microplus tick using the highest concentration $(10 \%)$, which caused a mortality of $80 \%$ of females on the 16th day. The concentrations of 5 and $2.5 \%$ essential oil led to a mortality rate of $60 \%$ and $35 \%$, respectively (Figure 1(b))

The toxic effect of the mixture of essential oils was also studied (Figure 1(c)). The mixture of C. limonum and $P$. nigrum oil induced $100 \%$ death at a concentration of $10 \%$ at the end of treatments. The results of the groups treated with the combination of the oils, at all concentrations tested, were very similar to the results of the C. limonum oil. These results demonstrate the dose-dependent character of $R$. (B.) microplus mortality and there was a significant difference between all treatments when compared with control group.

When AIT was performed with positive controls, the mortality of engorged females of $R$. (B.) microplus for Deltamethrin and Amitraz was $57.7 \%$ and $27.7 \%$, showing a level of resistance status (Figure $1(\mathrm{~d})$ )

Table 2 summarizes LC50 and LC90 values for individuals and combined treatments of C. limonum and P. nigrum oils against engorged females. The most potent modified oil was C. limonum with a LC90 of $4.9 \%$ whereas the combined oils exhibited a LC90 of 5.1\%.

3.3. Effect of Essential Oil of Citrus limonum, Piper nigrum, and Their Mixture on Rhipicephalus (Boophilus) microplus Female Oviposition and Hatching. In the AIT the efficacy of treatment against engorged females was also evaluated by measuring egg production. The results are presented in Table 3. Ours results showed that C. limonum and the oil mixture have the best inhibition of oviposition rate, which is $100 \%$ in a dilution of $10 \%$. However, at $5 \%$ the group with combined oils exhibited greater inhibition of oviposition with $94 \%$, compared to $81.6 \%$ inhibition by individual C. limonum. P. nigrum essential oil, at concentrations of $10 \%, 5 \%$, and $2.5 \%$, inhibited egg-laying by $96 \%, 83 \%$, and $50 \%$, respectively. Data were significantly different in relation to the control (DMSO $2 \%$ and water) group $(p<0.001)$. The few eggs laid by the females treated with $5 \%$ of $C$. limonum essential oil have not hatched into larvae. This result showed that oviposition is also dose-dependent (Table 3 ). Thus, analysis of variance $p<0.05$ for treatments confirmed the positive development of inhibition oviposition with increasing concentration. The mixture is effective against $R$. (B.) microplus engorged females since its effect is fast and is expressed at a low concentration on reducing the rate of lay. However, the essential oils did not interfere in the hatchability of the larvae.

\section{Discussion}

The analysis of chemical composition of Citrus limonum essential oil by GC/MS showed as major compounds limonene (50.3\%), $\beta$-pinene (14.4\%), and $\gamma$-terpinene $(11.7 \%)$. This result agrees with that found by others groups in previous studies with species of genus Citrus, where the same chemical compounds can be found, although in different 
TABle 1: Percentage composition of Citrus limonum and Piper nigrum oils.

\begin{tabular}{|c|c|c|c|}
\hline Constituents & $\mathrm{RI}$ & Citrus limonum (\%) & Piper nigrum (\%) \\
\hline \multicolumn{4}{|l|}{ Monoterpenes hydrocarbons } \\
\hline$\alpha$-Thujene & 927 & 0.6 & 1.0 \\
\hline$\alpha$-Pinene & 935 & 2.6 & 5.5 \\
\hline Camphene & 950 & 0.1 & - \\
\hline Sabinene & 975 & 2.8 & 0.9 \\
\hline$\beta$-Pinene & 978 & 14.4 & 4.1 \\
\hline Myrcene & 992 & 2.0 & 0.3 \\
\hline Phellandrene & 1007 & - & 4.1 \\
\hline$\delta$-3-Carene & 1013 & - & 0.9 \\
\hline$\alpha$-Terpinene & 1018 & 0.2 & 0.7 \\
\hline$\sigma$-Ocymene & 1026 & 2.9 & 5.8 \\
\hline Limonene & 1030 & 50.3 & 2.1 \\
\hline$\beta$-E-Ocymene & 1037 & 0.1 & - \\
\hline$\beta$-Z-Ocymene & 1048 & 0.1 & - \\
\hline$\gamma$ - Terpinene & 1060 & 11.8 & 0.5 \\
\hline Terpinolene & 1086 & 0.1 & - \\
\hline p-Mentha-2,4(8)-Diene & 1091 & - & 0.3 \\
\hline \multicolumn{4}{|l|}{ Oxygenated monoterpenes } \\
\hline 1,8-Cineol & 1034 & 0.1 & - \\
\hline Linalool & 1101 & 0.2 & - \\
\hline Limonene oxide -cis & 1135 & 0.1 & - \\
\hline Limonene oxide -trans & 1139 & 0.1 & - \\
\hline Carvenon & 1147 & 0.1 & - \\
\hline Terpinen-4-ol & 1178 & 0.1 & - \\
\hline$\alpha$-Terpineol & 1191 & 0.4 & 0.1 \\
\hline Nerol & 1224 & 0.1 & - \\
\hline Neral & 1242 & 1.1 & - \\
\hline \multicolumn{4}{|l|}{ Sesquiterpene hydrocarbons } \\
\hline$\delta$-Elemene & 1340 & - & 0.9 \\
\hline$\alpha$-Cubebene & 1353 & - & 0.5 \\
\hline$\alpha$-Copaene & 1379 & - & 4.2 \\
\hline$\beta$-Cubebene & 1383 & - & 0.2 \\
\hline$\beta$-Elemene & 1395 & - & 1.1 \\
\hline Cyperene & 1404 & - & 0.2 \\
\hline Bergamotene & 1418 & 0.04 & - \\
\hline$\beta$-Caryophyllene & 1426 & - & 26.2 \\
\hline$\beta$-Copaene & 1429 & - & 0.2 \\
\hline Trans-Bergamotene & 1439 & - & 3.9 \\
\hline$\alpha$-Germanene & 1443 & - & 0.5 \\
\hline (z)- $\beta$-Farnese & 1446 & - & 0.2 \\
\hline$\alpha$-Humulene & 1458 & - & 2.9 \\
\hline 9- EPI - (E)-Caryophyllene & 1466 & - & 0.3 \\
\hline$\gamma$-Muurolene & 1481 & - & 0.9 \\
\hline Trans-Muurola-4(14),5-Diene & 1485 & - & 1.5 \\
\hline
\end{tabular}


TABle 1: Continued.

\begin{tabular}{|c|c|c|c|}
\hline Constituents & RI & Citrus limonum (\%) & Piper nigrum (\%) \\
\hline$\beta$-Selinene & 1491 & - & 1.1 \\
\hline$\alpha$-Selinene & 1499 & - & 1.1 \\
\hline Bisabolene & 1506 & 0.1 & - \\
\hline$\beta$-Bisabolene & 1512 & 1.8 & 4.1 \\
\hline$\gamma$-Cadinene & 1519 & - & 0.6 \\
\hline$\delta$-Cadinene & 1528 & - & 2.1 \\
\hline Germacrene B & 1562 & - & 0.5 \\
\hline \multicolumn{4}{|l|}{ Oxygenated sesquiterpenes } \\
\hline Bergamotol $\alpha$-trans & 1439 & 1.1 & - \\
\hline Caryophyllene oxide & 1589 & - & 4.2 \\
\hline Junenol & 1624 & - & 0.6 \\
\hline Epi- $\alpha$-Muurolol & 1648 & - & 0.4 \\
\hline$\alpha$-Muurolol & 1652 & - & 0.3 \\
\hline$\alpha$-Cadinol & 1660 & - & 0.4 \\
\hline \multicolumn{4}{|l|}{ Others } \\
\hline Neril format & 1272 & 1.9 & - \\
\hline Neril acetate & 1367 & 0.9 & - \\
\hline Geranyl acetate & 1386 & 0.3 & - \\
\hline Guaiol acetate & 1729 & - & 0.7 \\
\hline Benzil benzoato & 1771 & - & 3.0 \\
\hline Manool & 2063 & - & 0.2 \\
\hline Total identified & & 96.3 & 89.0 \\
\hline
\end{tabular}

RI: retention index on DB-5MS column in reference to $n$-alkanes.

TABLE 2: LC50 and LC90 (\%) obtained for the engorged female of the essential oils of Citrus limonum, Piper nigrum, and their combination on R. microplus.

\begin{tabular}{lcc}
\hline Essential oil & LC50 (\%) & LC90 (\%) \\
\hline Citrus limonum & 2.2 & 4.9 \\
Piper nigrum & 3.7 & 14.8 \\
C. limonum + P. nigrum & 2.2 & 5.1 \\
\hline
\end{tabular}

proportions [26]. The essential oil chemical compositions of Piper nigrum consisted primarily of the sesquiterpene $\beta$-caryophyllene and the monoterpenes hydrocarbons $\sigma$ ocymene and $\alpha$-pinene, at 26.2\%, 5.8\%, and 5.5\%, respectively.

Essential oil from C. limonum exhibited greater activity on engorged females than $P$. nigrum, reaching a mortality of $100 \%$ at concentrations of $10 \%$, on 16 th day. The values of LC50 and LC90 of C. limonum were $2.2 \%$ and $4,9 \%$, respectively. P. nigrum exhibited LC50 of 3.7\% and LC90 of $14.8 \%$.

Components such as limonene and pinene have already been reported to possess acaricidal activity against ticks. Limonene, extracted from Lippia alba (Verbenaceae) essential oils of two chemotypes, demonstrated toxic effect on $R$. (B.) microplus larvae [27]. In another study, it was shown that limonene inhibited $91 \%$ of $R$. (B.) microplus hatching eggs at concentration of $1.25 \mu \mathrm{g} / \mathrm{mL}$ [28]. Moreover, this chemical constituent has also exhibited insecticide potential and proved to be highly toxic to mosquito larvae of Aedes aegypti (Diptera: Culicidae), Culex pipiens pallens (Diptera: Culicidae), and Ochlerotatus togoi (Diptera: Culicidae) [29], for grain insect pests stored Rhyzopertha dominica (Coleoptera: Bostrichidae) and Tribolium castaneum (Coleoptera: Tenebrionidae) [30] and lice Pediculus humanus capitis (Anoplura: Pediculidae) [31]. Acaricide activity in R. (B.) microplus larvae has also been demonstrated with essential oil of Cunila incana (Lamiaceae), rich in $\beta$-pinene (27.5\%) and $\alpha$-pinene $(26.7 \%)$, reaching $100 \%$ mortality with concentration of $2.5 \mu \mathrm{L} / \mathrm{mL}$ [32]. This suggests the major constituents of the essential oil are acting in an additive or added effect manner, thus contributing equally to the observed toxic effects. However, the added effect action of other minor constituents cannot be disregarded. Some studies have shown that essential oils have higher efficiency than their isolated components $[33,34]$.

Chungsamarnyart and Jansawan in [35] observed that the essential oil of Citrus maxima and Citrus sinensis showed over $90 \%$ mortality of $R$. (B.) microplus engorged females at a 


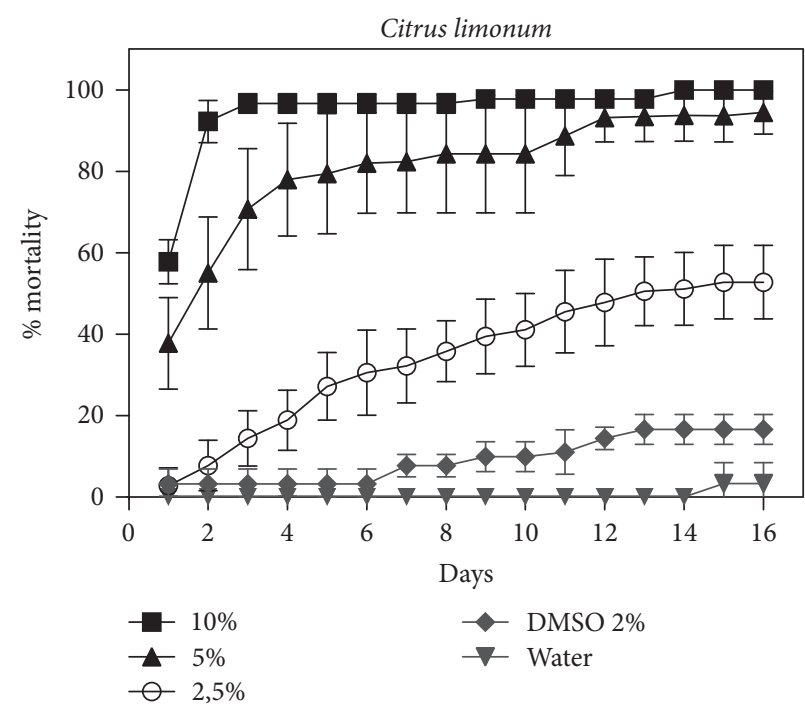

(a)

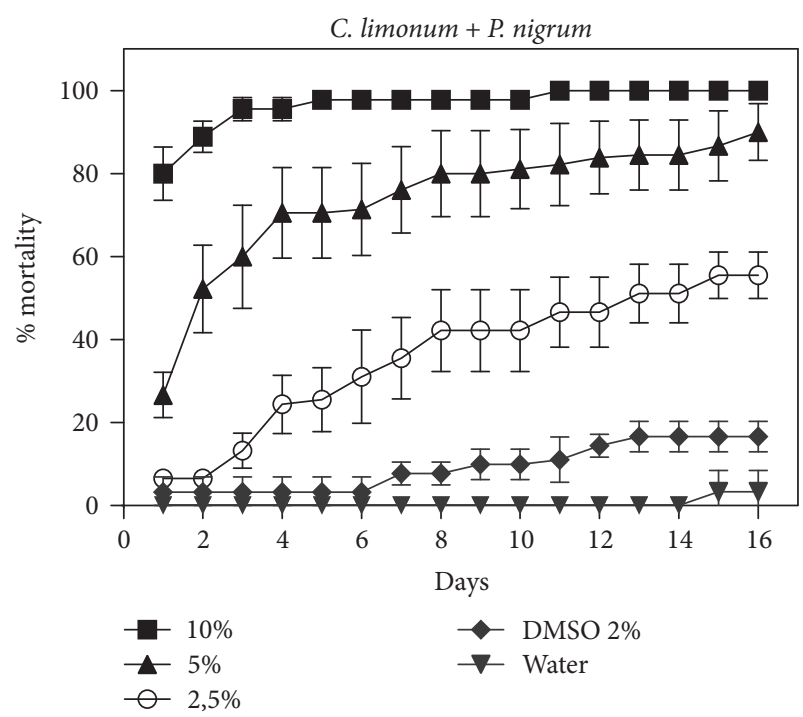

(c)

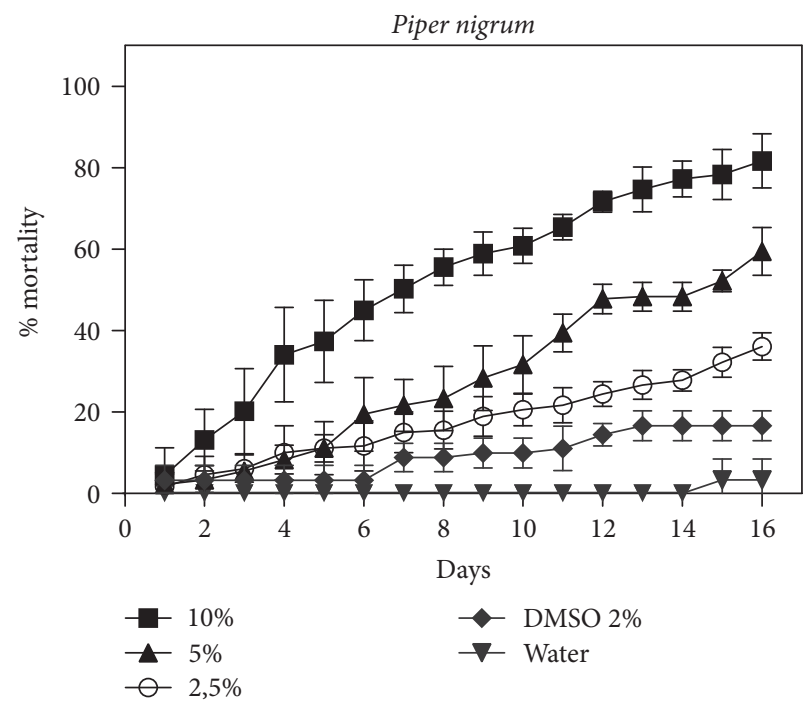

(b)

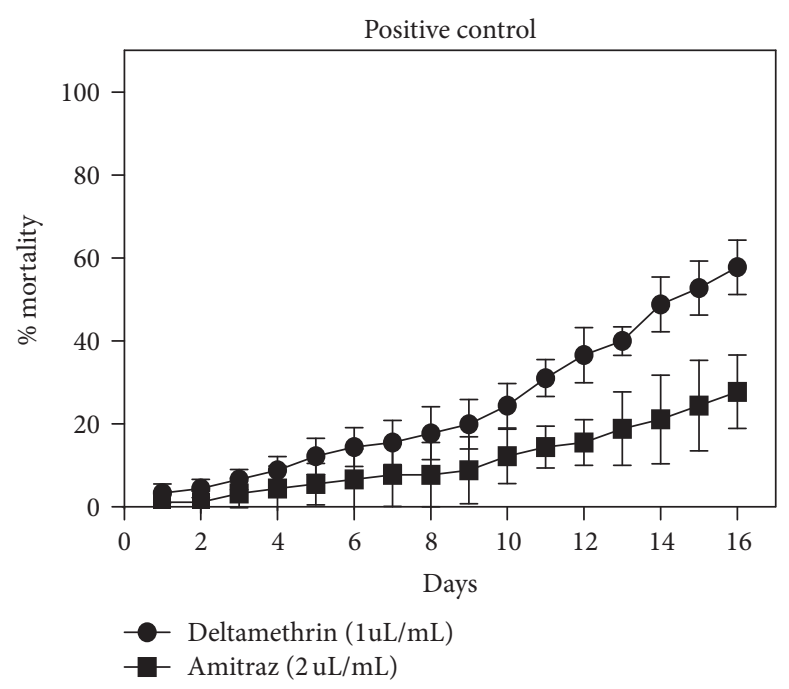

(d)

Figure 1: Mortality percentage of R. microplus engorged females exposed to Citrus limonum and Piper nigrum essential oil. Adult Immersion Test (AIT) on mortality of the tick R. microplus. Groups treated with different concentrations of essential oil of C. limonum (a), P. nigrum (b), the combination of both oils (c), and positive control were the commercial acaricides Deltamethrin and Amitraz. In combination oils used the $1: 1$ (vol/vol) concentration of each oil. Results are means \pm SD of five experiments.

concentration of $1 / 5$ in 24 hours. This concentration is higher than that found in our study. Already Citrus reticulata oil demonstrated a similar profile to $C$. limonum, reaching about $95 \%$ mortality within $24 \mathrm{~h}$ at a concentration of $1 / 10$. Plants of the same genus could have the same class of substances and so present similar activity. However, such substances may vary in concentration according to seasonality, circadian rhythm, and development of the plant [36].

Citrus limonum has already shown biological activity in several species of insects. The essential oil of C. limonum caused antifeedant activity in Spodoptera litura larvae (Lepidoptera: Noctuidae) and took the mortality Spodoptera littoralis larvae (Lepidoptera: Noctuidae) in the test by contact
[37, 38]. Pavela in [39] also demonstrated that essential oil of these specie showed fumigant and contact activity on the house fly Musca domestica (Diptera: Muscidae).

The reduction in the number of $C$. limonum eggs is probably due to female mortality in the first few days after treatment. However, it is possible that the essential oil of $P$. nigrum has caused a reduction in female's fecundity, since exposure to sublethal concentrations of the oil significantly reduced the number of eggs. The same effect was observed with the essential oil of Piper marginatum used as fumigant against the mite Tetranychus urticae (Acari: Tetranychidae), where the fecundity was drastically reduced. The $\beta$-caryophyllene was one of the main compounds (16\%) 
TABLE 3: Mortality percentage (MAM) of R. microplus engorged females, exposed to different concentrations of Citrus limonum and Piper nigrum, and effect reproductive index (RI), inhibition of oviposition (IO), and larvae hatching (LH).

\begin{tabular}{|c|c|c|c|c|}
\hline Concentration (\%) & $\operatorname{MAM}(\%) \pm \mathrm{SE}$ & $\mathrm{RI} \pm \mathrm{SE}$ & IO (\%) & $\mathrm{LH}$ \\
\hline \multicolumn{5}{|l|}{ Citrus limonum } \\
\hline $10 \%$ & $100.0 \pm 0.0^{\mathrm{a}, \mathrm{b}}$ & $0.0 \pm 0.0^{\mathrm{a}, \mathrm{b}}$ & 100 & - \\
\hline $5 \%$ & $94.4 \pm 5.7^{\mathrm{a}, \mathrm{b}}$ & $0.1 \pm 0.1^{\mathrm{a}, \mathrm{b}}$ & 81.6 & Without hatching \\
\hline $2.5 \%$ & $52.8 \pm 12.8^{\mathrm{a}, \mathrm{b}}$ & $0.3 \pm 0.1^{\mathrm{a}, \mathrm{b}}$ & 35 & There was hatching \\
\hline \multicolumn{5}{|l|}{ Piper nigrum } \\
\hline $10 \%$ & $81.7 \pm 6.7^{\mathrm{a}, \mathrm{b}}$ & $0.0 \pm 0.0^{\mathrm{a}, \mathrm{b}}$ & 96 & Without hatching \\
\hline $5 \%$ & $59.4 \pm 9.4^{\mathrm{a}, \mathrm{b}}$ & $0.1 \pm 0.0^{\mathrm{a}, \mathrm{b}}$ & 83 & There was hatching \\
\hline $2.5 \%$ & $36.1 \pm 3.9^{\mathrm{a}}$ & $0.2 \pm 0.0^{\mathrm{a}, \mathrm{b}}$ & 50 & There was hatching \\
\hline \multicolumn{5}{|l|}{ C. limonum + P. nigrum } \\
\hline $10 \%$ & $100.0 \pm 0.0^{\mathrm{a}, \mathrm{b}}$ & $0.0 \pm 0.0^{\mathrm{a}, \mathrm{b}}$ & 100 & - \\
\hline $5 \%$ & $90.0 \pm 10.0^{\mathrm{a}, \mathrm{b}}$ & $0.0 \pm 0.0^{\mathrm{a}, \mathrm{b}}$ & 94 & Without hatching \\
\hline $2.5 \%$ & $55.6 \pm 9.0^{\mathrm{a}, \mathrm{b}}$ & $0.1 \pm 0.0^{\mathrm{a}, \mathrm{b}}$ & 67 & There was hatching \\
\hline $\operatorname{Amitraz}(2 \mu \mathrm{L} / \mathrm{mL})$ & $27.8 \pm 7.9^{\mathrm{a}}$ & $0.0^{\mathrm{a}, \mathrm{b}}$ & 100 & - \\
\hline Deltamethrin $(1 \mu \mathrm{L} / \mathrm{mL})$ & $57.8 \pm 9.0^{\mathrm{a}, \mathrm{b}}$ & $0.0^{\mathrm{a}, \mathrm{b}}$ & 100 & - \\
\hline DMSO $2 \%$ & $16.7 \pm 3.4$ & $0.5 \pm 0.0$ & 0 & There was hatching \\
\hline Water & $3.3 \pm 3.3$ & $0.5 \pm 0.0$ & 0 & There was hatching \\
\hline
\end{tabular}

MAM: mean \% adult mortality within 16 days, SE: standard error, RI: reproductive index, IO: (\%) percent inhibition of oviposition, and LH: Larvae hatching after females treatment. ${ }^{a}$ Significant difference in relation to the negative control (water). ${ }^{\mathrm{b}}$ Significant difference in relation to the negative control (2\% DMSO) (ANOVA one way $p=<0.0001$ ).

found in the essential oil of P. marginatum, as well as the oil of $P$. nigrum in the present work. This constituent was also evaluated against T. urticae and this also reduced the females' fecundity in sublethal concentrations [40].

According to chemical analysis, the essential oil of $P$. nigrum majority has the sesquiterpene $\beta$-caryophyllene $(26.2 \%)$ and the monoterpenes hydrocarbons $\sigma$-ocymene (5.8\%) and $\alpha$-pinene (5.5\%). However, Ferreira et al. in [41] analyzed the essential oil from $P$. nigrum and found as main components the sesquiterpene $\beta$-caryophyllene $(21.8 \%)$ and the monoterpenes limonene $(19.8 \%)$ and $3-\sigma$-carene (14.3\%). The constituents of essential oils can vary with environmental conditions, such as climate, soil type and brightness. The biological properties of $\beta$-caryophyllene have been confirmed in previous studies involving Leptinotarsa decemlineata (Coleoptera: Chrysomelidae), S. littoralis [42], larvae of $A$. aegypti [43], and T. urticae [44]. The compound $\alpha$-pinene has been reported with insecticidal activity in larvae of C. pipiens [45] and as a fumigant against the adult mushroom fly Lycoriella mali (Diptera: Sciaridae) [46].

Plants of the genus Piper have demonstrated toxic effect on R. (B.) microplus. Ferraz et al. in [47] showed that the essential oils of Piper mikanianum and Piper xylosteoides were active against $R$. (B.) microplus larvae (LC50 of 2.3 and $6.2 \mu \mathrm{L} / \mathrm{mL}$, resp.). Piper tuberculatum and Piper aduncum extracts were also highly effective against the larvae and engorged female tick $R$. (B.) microplus $[48,49]$. In addition, other studies have shown that the essential oil of $P$. nigrum has insecticidal activity against mosquitoes $A$. aegypti, A. stephensi (Diptera: Culicidae), and C. quinquefasciatus (Diptera: Culicidae) [50].

Ours results showed that the oil mixture has a high acaricidal activity on engorged females of $R$. (B.) microplus, reaching $100 \%$ mortality, at a concentration a little larger than that of the C. limonum essential oil (LC90 = 4,9\%). However, the oils combination showed to be more effective in the inhibition of oviposition compared to the oil C. limonum. Considering that $C$. limonum oil caused high mortality of females and $P$. nigrum oil reduced fertility, it is possible that the essential oils have an additive effect when mixed in the same solution, exhibiting both effects against $R$ (B.) microplus tick females. Yessinou et al. in [51] recently showed that the mixture of Syzygium aromaticum (Myrtaceae) and Cymbopogon citratus (Poaceae) essential oils was more effective in engorged females of $R$. (B.) microplus than when tested separately, confirming the action potential of essential oils when used simultaneously.

\section{Conclusion}

This study demonstrates that the essential oil of lemon has a high acaricide activity against the tick $R$. (B.) microplus, especially in its engorged female and egg stages, cutting its cycle. Thus, it can be a possible candidate for biocontrol against this cattle tick.

\section{Conflicts of Interest}

The authors declare that they have no conflicts of interest.

\section{Acknowledgments}

The authors are grateful to FAPERJ, CNPq FOPESQ-UFF for financial support to the present work. 


\section{References}

[1] S. C. Horn and C. C. P. Arteche, "Situação parasitária da pecuária no Brasil," A Hora Veterinária, vol. 4, pp. 12-32, 1985.

[2] A. Murrell and S. C. Barker, "Synonymy of Boophilus Curtice, 1891 with Rhipicephalus Koch, 1844 (Acari: Ixodidae), Systematic Parasitology, vol. 56, no. 3, pp. 169-172, 2003.

[3] F. C. Santos, F. S. Vogel, and S. G. Monteiro, "Efeito do óleo essencial de manjericão (Ocimum basilicum L.) sobre o carrapato bovino Rhipicephalus (Boophilus) microplus em ensaios in vitro," Semina: Ciências Agrárias, vol. 33, no. 3, pp. 1133-1140, 2012.

[4] R. Andreotti, "Situação atual da resistência do carrapato-doboi Rhipicephalus(Boophilus) microplusaos acaricidas no Brasil," Embrapa Gado de Corte, 36 pages, 2010.

[5] L. Grisi, R. C. Leite, J. R. D. S. Martins et al., "Reassessment of the potential economic impact of cattle parasites in Brazil," Revista Brasileira de Parasitologia Veterinaria, vol. 23, no. 2, pp. 150-156, 2014.

[6] J. R. Martins, D. E. Evans, V. H. Cereser, and B. L. Corrêa, "Partial strategic tick control within a herd of Europeanbreed cattle in the state of Rio Grande do Sul, southern Brazil," Experimental Applied Acarology, vol. 27, pp. 241-251, 2002.

[7] L. G. Brito, F. S. Barbieri, R. B. Rocha, M. C. S. Oliveira, and E. S. Ribeiro, "Evaluation of the efficacy of acaricides used to control the cattle tick, Rhipicephalus microplus, in Dairy Herds raised in the Brazilian Southwestern Amazon," Veterinary Medicine International, vol. 2011, Article ID 806093, 6 pages, 2011.

[8] S. Ghosh, P. Azhahianambia, and M. P. Yadavb, "Upcoming and future strategies of tick control: a review," Journal of Vector Borne Disease, vol. 44, pp. 79-89, 2007.

[9] R. Ravindran, S. Juliet, A. R. Sunil et al., "Eclosion blocking effect of ethanolic extract of Leucas aspera (Lamiaceae) on Rhipicephalus (Boophilus) annulatus," Veterinary Parasitology, vol. 179, no. 1-3, pp. 287-290, 2011.

[10] G. P. Georghiou and A. Lagunes-Tejada, The Occurrence of Resistance to Pesticide in Arthropods: An Index of Cases Reported through, FAO, 1989.

[11] K. Pirali-Kheirabadi and M. Razzaghi-Abyaneh, "Biological activities of chamomile (Matricaria chamomile) flowers' extract against the survival and egg laying of the cattle fever tick (Acari Ixodidae).", Journal of Zhejiang University. Science. B., vol. 8, no. 9, pp. 693-696, 2007.

[12] L. Ellse and R. Wall, "The use of essential oils in veterinary ectoparasite control: A review," Medical and Veterinary Entomology, vol. 28, no. 3, pp. 233-243, 2014.

[13] J. R. Pirani and M. Groppo, Rutaceae in Lista de Espécies da Flora do Brasil.Jardim Botânico do Rio de Janeiro, 2013, http://floradobrasil.jbrj.gov.br/jabot/floradobrasil/FB212.

[14] S. Panizza, Plantas que curam. 28 ed. São Paulo, SP: IBRASA, 279p, 1997.

[15] M. G. S. Vieira, J. V. B. De Freitas, M. N. De Lima Neto, N. V. Gramosa, and E. P. Nunes, "Volatile chemical constituents of the leaves and twigs from Zanthoxylum syncarpum Tull," Quimica Nova, vol. 32, no. 2, pp. 391-393, 2009.

[16] A. K. Boehme, J. A. Noletto, W. A. Haber, and W. N. Setzer, "Bioactivity and chemical composition of the leaf essential oils of Zanthoxylum rhoifolium and Zanthoxylum setulosum from Monteverde, Costa Rica," Natural Product Research, vol. 22, no. 1, pp. 31-36, 2008.

[17] R. Ramakrishnan Nair and S. Dutta Gupta, "Somatic embryogenesis and plant regeneration in black pepper (Piper nigrum
L.): I. Direct somatic embryogenesis from tissues of germinating seeds and ontogeny of somatic embryos," Journal of Horticultural Science and Biotechnology, vol. 78, no. 3, pp. 416-421, 2003.

[18] B. H. Abbasi, N. Ahmad, H. Fazal, and T. Mahmood, "Conventional and modern propagation techniques in Piper nigrum," Journal of Medicinal Plants Research, vol. 4, no. 1, pp. 007-012, 2010.

[19] S. Khan, K. J. Mirza, F. Anwar, and M. Zainulabdin, "Development of RAPD markers for authentication of Piper nigrum(L.)," International Journal of Science and Technology, vol. 5, pp. 4756, 2010.

[20] N. Ahmad, H. Fazal, B. H. Abbasi, S. Farooq, M. Ali, and M. A. Khan, "Biological role of Piper nigrum L. (Black pepper): A review," Asian Pacific Journal of Tropical Biomedicine, vol. 2, no. 3, pp. S1945-S1953, 2012.

[21] C. Ferreira, D. C. Soares, C. B. Barreto-Junior et al., "Leishmanicidal effects of piperine, its derivatives, and analogues on Leishmania amazonensis," Phytochemistry, vol. 72, no. 17, pp. 2155-2164, 2011.

[22] I. M. Scott, H. R. Jensen, B. J. R. Philogène, and J. T. Arnason, "A review of Piper spp. (Piperaceae) phytochemistry, insecticidal activity and mode of action," Phytochemistry Reviews, vol. 7, no. 1, pp. 65-75, 2008.

[23] R. P. Adams, Identification of essential oil components by gas chromatography/mass spectrometry, Allured Publishing, Carol Stream, Ill, USA, 4th edition, 2007.

[24] Z. C. Gazim, I. G. Demarchi, M. V. C. Lonardoni et al., "Acaricidal activity of the essential oil from Tetradenia riparia (Lamiaceae) on the cattle tick Rhipicephalus (Boophilus) microplus (Acari; Ixodidae)," Experimental Parasitology, vol. 129, no. 2, pp. 175-178, 2011.

[25] R. O. Drummond, S. E. Ernst, J. L. Trevino, W. J. Gladney, and O. H. Graham, "Boophilus annulatus and Boophilus microplus: laboratory tests for insecticides," Journal of Economic Entomology, vol. 66, no. 1, pp. 130-133, 1973.

[26] A. M. Pohlit, A. R. Rezende, E. L. Lopes Baldin, N. P. Lopes, and V. F. de Andrade Neto, "Plant Extracts, isolated phytochemicals, and plant-derived agents which are lethal to arthropod vectors of human tropical diseases-a review," Planta Medica, vol. 77, pp. 618-630, 2011.

[27] M. G. Peixoto, L. M. Costa-Júnior, A. F. Blank et al., “Acaricidal activity of essential oils from Lippia alba genotypes and its major components carvone, limonene, and citral against Rhipicephalus microplus," Veterinary Parasitology, vol. 210, no. 1-2, pp. 118-122, 2015.

[28] S. R. Ferrarini, M. O. Duarte, R. G. da Rosa et al., "Acaricidal activity of limonene, limonene oxide and b-aminoalcohol derivatives on Rhipicephalus (Boophilus) microplus," Veterinary Parasitology, vol. 157, no. 1-2, pp. 149-153, 2008.

[29] H. Perumalsamy, N.-J. Kim, and Y.-J. Ahn, "Larvicidal activity of compounds isolated from asarum heterotropoides against culex pipiens pallens, aedes aegypti, and ochlerotatus togoi (diptera: Culicidae)," Journal of Medical Entomology, vol. 46, no. 6, pp. 1420-1423, 2009.

[30] H. T. Prates, J. P. Santos, J. M. Waquil, J. D. Fabris, A. B. Oliveira, and J. E. Foster, "Insecticidal activity of monoterpenes against rhyzopertha dominica (F.) and Tribolium castaneum (Herbst)," Journal of Stored Products Research, vol. 34, no. 4, pp. 243-249, 1998.

[31] A. C. Toloza, C. Vassena, and M. I. Picollo, "Ovicidal and adulticidal effects of monoterpenoids against permethrin-resistant 
human head lice, Pediculus humanus capitis," Medical and Veterinary Entomology, vol. 22, no. 4, pp. 335-339, 2008.

[32] M. A. Apel, V. L. Sardá Ribeiro, S. A. L. Bordignon, A. T. Henriques, and G. Von Poser, "Chemical composition and toxicity of the essential oils from Cunila species (Lamiaceae) on the cattle tick Rhipicephalus (Boophilus) microplus," Parasitology Research, vol. 105, no. 3, pp. 863-868, 2009.

[33] S. Miresmailli, R. Bradbury, and M. B. Isman, "Comparative toxicity of Rosmarinus officinalis L. essential oil and blends of its major constituents against Tetranychus urticae Koch (Acari: Tetranychidae) on two different host plants," Pest Management Science, vol. 62, no. 4, pp. 366-371, 2006.

[34] R. Singh, O. Koul, P. J. Rup, and J. Jindal, "Toxicity of some essential oil constituents and their binary mixtures against Chilo partellus (Lepidoptera: Pyralidae)," International Journal of Tropical Insect Science, vol. 29, no. 2, pp. 93-101, 2009.

[35] N. Chungsamarnyart and W. Jansawan, "Acaricidal activity of peel oil of Citrus spp. on Boophilus microplus," Kasetsart Journal of Natural Science, vol. 30, pp. 112-117, 1996.

[36] L. Gobbo-Neto and N. P. Lopes, "Plantas medicinais: fatores de influência no conteúdo de metabólitos secundários," Química Nova, vol. 30, no. 2, pp. 374-381, 2007.

[37] K. Elumalai, K. Krishnappa, and A. Anandan, "Antifeedant activity of medicinal plant essential oils against Spodoptera litura (Lepidoptera: Noctuidae)," International Journal of Records Science Research, vol. 2, pp. 062-068, 2010.

[38] R. Pavela, "Insecticidal activity of some essential oils against larvae of Spodoptera littoralis," Fitoterapia, vol. 76, no. 7-8, pp. 691-696, 2005.

[39] R. Pavela, "Insecticidal properties of several essential oils on the house fly (Musca domestica L.)," Phytotherapy Research, vol. 22, no. 2, pp. 274-278, 2008.

[40] N. Ribeiro, C. Camara, and C. Ramos, "Toxicity of essential oils of piper marginatum Jacq. against Tetranychus urticae Koch and Neoseiulus Californicus (McGregor)," Chilean Journal of Agricultural Research, vol. 76, no. 1, pp. 71-76, 2016.

[41] S. R. S. Ferreira, Z. L. Nikolov, L. K. Doraiswamy, M. A. A. Meireles, and A. J. Petenate, "Supercritical fluid extraction of black pepper (Piper nigrun L.) essential oil," Journal of Supercritical Fluids, vol. 14, no. 3, pp. 235-245, 1999.

[42] J. M. Rodilla, M. T. Tinoco, J. C. Morais et al., "Laurus novocanariensis essential oil: Seasonal variation and valorization," Biochemical Systematics and Ecology, vol. 36, no. 3, pp. 167-176, 2008.

[43] G. A. A. Dória, W. J. Silva, G. A. Carvalho, P. B. Alves, and S. C. H. Cavalcanti, "A study of the larvicidal activity of two Croton species from northeastern Brazil against Aedes aegypti," Pharmaceutical Biology, vol. 48, no. 6, pp. 615-620, 2010.

[44] M. J. C. Araújo, C. A. G. Câmara, F. S. Born, M. M. Moraes, and C. A. Badji, "Acaricidal activity and repellency of essential oil from Piper aduncum and its components against Tetranychus urticae," Experimental and Applied Acarology, vol. 57, no. 2, pp. 139-155, 2012.

[45] A. F. Traboulsi, K. Taoubi, S. El-Haj, J. M. Bessiere, and S. Rammal, "Insecticidal properties of essential plant oils against the mosquito Culex pipiens molestus (Diptera: Culicidae)," Pest Management Science, vol. 58, no. 5, pp. 491-495, 2002.

[46] W.-S. Choi, B.-S. Park, Y.-H. Lee, D. Y. Jang, H. Y. Yoon, and S.E. Lee, "Fumigant toxicities of essential oils and monoterpenes against Lycoriella mali adults," Crop Protection, vol. 25, no. 4, pp. 398-401, 2006.
[47] A. B. F. Ferraz, J. M. Balbino, C. A. Zini, V. L. S. Ribeiro, S. A. L. Bordignon, and G. Von Poser, "Acaricidal activity and chemical composition of the essential oil from three Piper species," Parasitology Research, vol. 107, no. 1, pp. 243-248, 2010.

[48] W. C. Silva, J. R. de Souza Martins, H. E. M. de Souza et al., "Toxicity of Piper aduncum L. (Piperales: Piperaceae) from the Amazon forest for the cattle tick Rhipicephalus (Boophilus) microplus (Acari: Ixodidae)," Veterinary Parasitology, vol. 164, no. 2-4, pp. 267-274, 2009.

[49] A. Da Silva Lima, J. G. Do Nascimento Sousa Filho, S. Garcia Pereira, G. M. Skelding Pinheiro Guillon, L. Da Silva Santos, and L. M. Costa Júnior, "Acaricide activity of different extracts from Piper tuberculatum fruits against Rhipicephalus microplus," Parasitology Research, vol. 113, no. 1, pp. 107-112, 2014.

[50] I.-K. Park, S.-G. Lee, S.-C. Shin, J.-D. Park, and Y.-J. Ahn, "Larvicidal activity of isobutylamides identified in Piper nigrum fruits against three mosquito species," Journal of Agricultural and Food Chemistry, vol. 50, no. 7, pp. 1866-1870, 2002.

[51] R. E. Yessinou, J. Adinci, and P. Sessou, "In vitro acaricidal effect of Syzygium aromaticum and Cymbopogon citratus essential oil on engorged female of cattle tick Rhipicephalus microplus in Benin," Scientific Journal of Veterinary Advances, vol. 5, no. 3, pp. 80-86, 2016. 

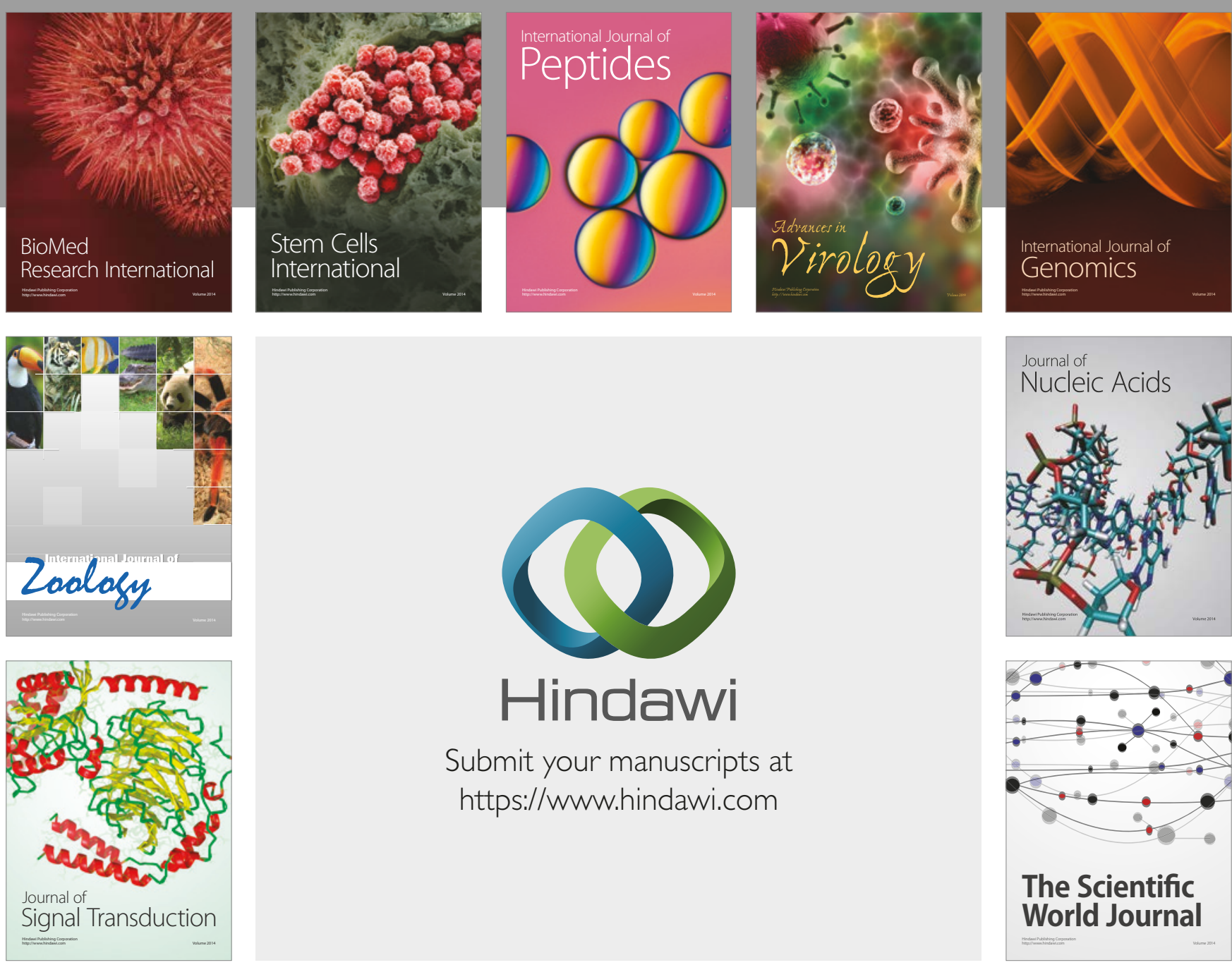

Submit your manuscripts at

https://www.hindawi.com
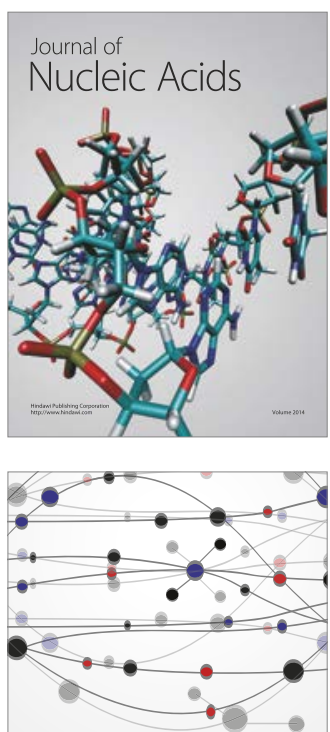

The Scientific World Journal

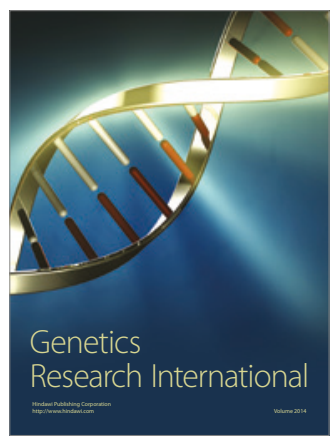

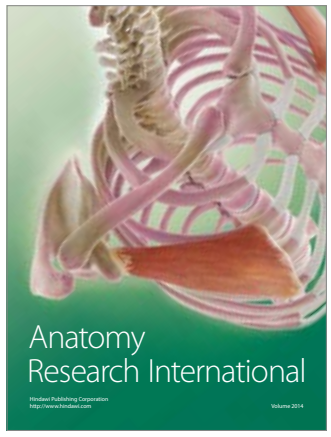

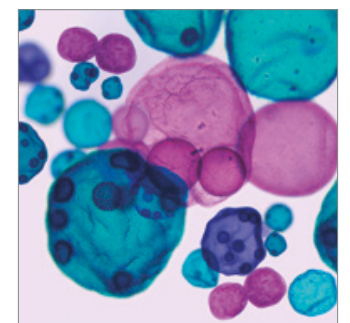

International Journal of Microbiology
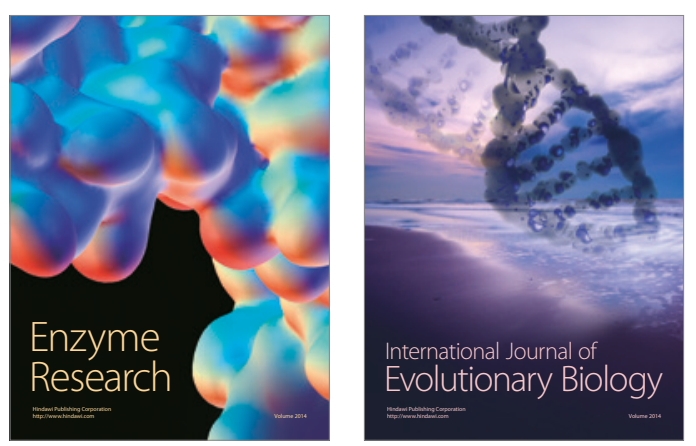
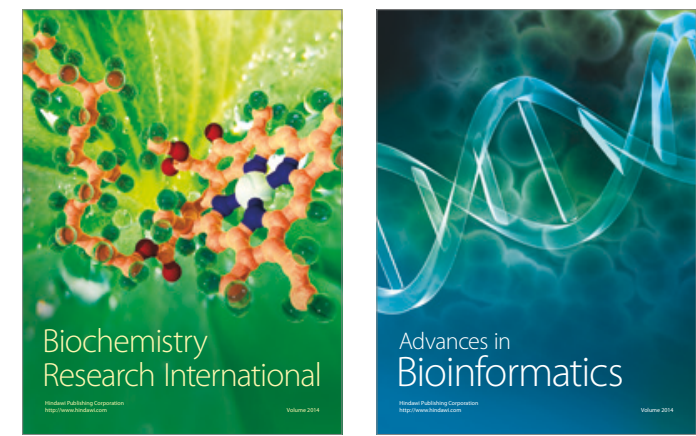

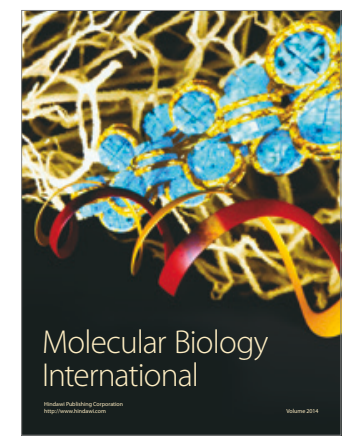

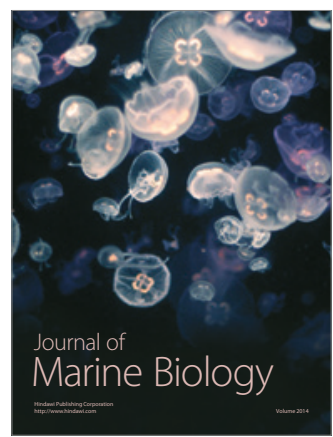

